\title{
REDES VIRTUAIS DE APRENDIZAGEM NA SOCIEDADE E NA PESQUISA
}

\author{
VIRTUAL LEARNING NETWORK IN SOCIETY AND RESEARCH
}

\author{
Gustavo Henrique de Araújo Freire - ghafreire@uol.com.br \\ Doutor em Ciência da Informação (IBICT - UFRJ) \\ Programa de Pós-Graduação em Ciência da Informação \\ Universidade Federal da Paraíba
}

\begin{abstract}
Resumo
Apresenta um dos aspectos da tese de que uma rede virtual de aprendizagem (aqui denominada estoques de informação em fluxo) facilita a comunicação da informação nos grupos de usuários que dela participa. Aponta que a principal característica da sociedade contemporânea é a aplicação da informação e do conhecimento em um ciclo de realimentação cumulativo da inovação tecnológica. Discute o valor do capital intelectual para o processo de produção social, o que vem a exigir a constante atualização dos estoques dinâmicos de informação armazenados nos indivíduos. Define o papel dos profissionais da informação a partir da responsabilidade social de facilitar a comunicação da informação para um usuário que dela necessita, no processo de construção do seu próprio conhecimento. Propõe que as redes de aprendizagem assumam o papel fundamental de meio não somente na comunicação da informação, mas, especialmente, na criação de possibilidades de produção de novos conhecimentos.
\end{abstract}

Palavras-chave: Redes virtuais de aprendizagem. Comunicação da informação. Gestão da Informação. Ciência da Informação. Profissionais da informação.

\section{INTRODUÇÃO}

Neste trabalho, apresentamos um dos aspectos da tese de que uma rede virtual de aprendizagem (aqui denominada estoques de informação em fluxo) facilita a comunicação da informação nos grupos de usuários que dela participa. ${ }^{1}$ Nesse sentido, pode favorecer o compartilhamento da informação, aumentando a possibilidade de geração de novos conhecimentos em seus usuários.

Nossa premissa é de que a informação sempre foi importante no desenvolvimento sócio-cultural da humanidade, mas ganha uma nova relevância na sociedade contemporânea, traduzindo-se em números expressivos de produtos e serviços ligados à sua geração e disseminação. Nesse processo histórico, as relações sociais se tornaram menos hierarquizadas e as tecnologias digitais de informação e comunicação passaram a ter um importante papel na produção social e no contexto cultural. Pois, segundo Castells, a principal característica da atual revolução tecnológica não é propriamente a centralidade na informação e no conhecimento, 
...mas a aplicação desses conhecimentos e dessa informação para a geração de conhecimentos e dispositivos de processamento/comunicação da informação, em um ciclo de realimentação cumulativo entre a inovação e o seu uso (CASTELLS, 1999, p. 50).

É assim que, por estar centrada na informação e no conhecimento, a sociedade contemporânea valoriza o "capital intelectual", 2 exigindo a constante atualização dos estoques de informação, ou estruturas significantes com a competência de gerar conhecimento, as quais, conforme Barreto (1999),

...são armazenadas ou estocadas no que denominamos de agregados de informação: unidades que produzem e armazenam o conhecimento produzido. Essas unidades elaboram os diferentes estoques de saber acumulado nas diferentes áreas das Ciências Humanas. Os agregados de informação e conhecimento podem ser pessoas, inscrições de informação (documentos), conjunto de documentos em diferentes formatos, acervos, metodologias, construtos teóricos ou de aplicação prática específica. (BARRETO, 1999).

Este é o quadro de referência a partir do qual elaboramos nossas reflexões sobre o papel do profissional da informação no cenário da sociedade em rede. A nosso ver, este papel se define a partir da responsabilidade social de facilitar a comunicação da informação para um usuário que dela necessita para a construção do seu próprio conhecimento. ${ }^{3} \mathrm{E}$ nessa perspectiva, as redes de aprendizagem assumem um papel fundamental, não somente na comunicação da informação, mas, especialmente, na criação de possibilidades de produção de novos conhecimentos. Por isso mesmo, sua abordagem torna-se relevante no contexto da pesquisa, não somente para a Ciência da Informação, mas para o campo científico em geral.

\section{REDES DE COMUNICAÇÃO DA INFORMAÇÃO}

$\mathrm{Na}$ nossa perspectiva, as redes de comunicação constituem estoques de informação em fluxo. O ciberespaço ${ }^{4}$ é o local onde circulam esses estoques de informação ${ }^{5}$ e, também, onde estes já são diretamente concebidos e produzidos. Neste espaço de produção e comunicação da informação existe uma dinâmica própria, em que novas relações e articulações estão sendo construídas a todo instante. Nesse sentido, podemos pensar em estoques de informação na Internet e na possibilidade de uso por usuários diversificados, embora não se possa assegurar que os estoques de informação poderão ser acessados quando necessário, por variados motivos: sites fora do ar, mudança de endereço e outros. Ou seja, as informações que circulam na rede se aproximam mais de uma "possibilidade de informação" relacionada às inúmeras oportunidades oferecidas

\footnotetext{
2 Segundo Stewart, "o capital intelectual constitui a matéria-prima intelectual — conhecimento, informação, propriedade intelectual, experiência - que pode ser utilizada para gerar riqueza. É a capacidade mental coletiva" (STEWART, 1998, p.13).

3 A propósito, ver WERSIG e NEVELING, 1975 e FREIRE, 2001.

4 Cf. LEVY, 1996.

5 Usamos o termo no sentido proposto por Barreto (1996), em seu modelo dos agregados de informação.
} 
no espaço virtual da rede, do que de uma busca concreta na materialidade das inúmeras fontes de informação, digitais ou não, disponíveis.

Diante disso, idéias como tempo e espaço precisam ser revistas. Em relação ao tempo ${ }^{6}$, prevalece o presente, ou seja, o momento em que estamos conectados; já a noção de espaço passa a ser radicalmente alterada, visto que, conectando-se do Rio de Janeiro (por exemplo), um usuário pode levar o mesmo tempo para ter acesso ao site da UFRJ (no Brasil) ou ao do MIT (nos EUA). ${ }^{7}$ Desse modo, apesar das várias analogias que se possa fazer com o "mundo real", o ciberespaço, necessariamente, implica novas atitudes nas pessoas, principalmente na área cognitiva, onde ocorrem os fenômenos da informação semântica.

Os símbolos são fundamentais para que o processo de comunicação humana possa existir. A mensagem é composta por símbolos que, ao se unirem, podem conter um significado e transmitir uma informação que poderá vir a ser assimilada e, conseqüentemente, transformada em conhecimento por um receptor. A possibilidade de construção de símbolos no ciberespaço pode provocar novas atitudes em relação à própria construção do texto em si mesmo. A palavra escrita, com sua aura de permanência e historicidade, é colocada em xeque, pois passa a fazer parte de um espaço comunicacional em que a mudança parece ser a norma e o compromisso fica apenas com o tempo presente. E assim, podemos escrever textos coletivos, mudarmos o que escrevemos "ontem" e, talvez, o mais interessante, utilizar todos os símbolos existentes em uma mesma estrutura significante, como num hipertexto digital, em que reunimos conteúdos em linguagem escrita, gráficos, fotos, imagens em movimento, voz. Dessa forma, a construção de símbolos adota uma complexidade nunca antes vista pela humanidade, tornada possível através da convergência de todas as tecnologias intelectuais disponíveis na cultura humana, e incrementadas pela tecnologia digital.

Nossa abordagem se adentra no sentido de investigar como se apresenta a relação entre informação e conhecimento em um ambiente de comunicação em rede. Entendemos que a informação é um fenômeno social produzido por indivíduos em um determinado contexto, representando uma "possibilidade objetiva de conhecimento" com valor econômico e cultural, circulando no mesmo espaço de comunicação social em que interagem os demais tipos de conhecimento, mas se distinguindo destes por sua expressão explícita e pública, em contraposição ao "conhecimento tácito". ${ }^{8}$

6 De certa forma, o que chamamos de "tempo" é uma convenção inventada pelo Homem para marcar fatos e poder narrar sua passagem pelo Planeta. Os primeiros registros temporais surgem a partir do momento em que a humanidade deixa de ser nômade, passando a se fixar em pequenos grupos para trabalhar com a agricultura, e assim surge a necessidade de observar as mudanças que ocorrem na natureza com seus ciclos climáticos representados pelas quatro estações.

$7 \quad$ UFRJ $=$ Universidade Federal do Rio de Janeiro. MIT = Massachusetts Institute of Tecnhology.

8 Para alguns autores, o "conhecimento tácito" é aquele que só pode ser transmitido de pessoa para pessoa, sendo difícil de ser explicitado. Este modelo de abordagem trabalha com três tipos de conhecimento: conhecimento em si, conhecimento tácito e conhecimento codificado (que pode ser visto como "informação"). No presente trabalho, pensamos em sintonia com autores da Ciência da Informação que abordam o conhecimento como um processo cognitivo realizado na mente de cada indivíduo de maneira distinta. Nessa perspectiva, a "informação" ocorre quando um alguém exterioriza seu conhecimento, usando como suporte qualquer código lingüístico que possua um significado possível para um dado receptor, podendo vir a gerar conhecimento num indivíduo ou, mesmo, no grupo. 
O conhecimento tácito é um tipo de conhecimento que nos acompanha desde os primórdios da evolução humana, quando só existia a comunicação oral, ou seja, um tempo em que ainda não existiam signos gráficos. Esse fato está fortemente baseado nas experiências vividas pelas pessoas, e sempre foi fundamental para a transmissão da informação, já que todos que faziam parte do grupo deveriam ter acesso às informações. Era uma época em que o registro escrito ainda não tinha sido inventado, e as formas para a fixação de informações eram baseadas na oralidade através de contadores de histórias, da música. Com a criação da linguagem escrita, surgiu a possibilidade de se perpetuar esse conhecimento e iniciou-se um processo no qual o conhecimento baseado na prática é lentamente camuflado por causa da dificuldade insolúvel de transcrição da linguagem falada para a escrita. A partir da criação de tecnologias que preservam a linguagem oral com o mesmo padrão e significados do momento de sua geração (gravadores, vídeos analógicos entre outros), e mais recentemente com as tecnologias digitais, os padrões da linguagem oral se tornaram mais presentes no processo formal de comunicação. $\mathrm{O}$ uso da linguagem natural por parte dos computadores, possibilitando aos usuários participarem ativamente do processo de produção do conhecimento, trouxe um novo impulso a uma sociedade que já se preparava, desde a criação das primeiras universidades no século XII, para o uso intensivo de informação e conhecimento.

\section{REDES DE APRENDIZAGEM: UM ESPAÇO DE COMUNICAÇÃO}

Após a descoberta de como fazer o fogo, fundamental na nossa trajetória evolutiva, o ser humano criou diversas formas de produção de seus artefatos e passamos de coletores de frutas a coletores de informação. Antes, a nossa espécie procurava as melhores áreas de pesca, de caça, e a localização desses lugares poderia ser uma informação relevante para o desenvolvimento de uma comunidade específica. Hoje, buscamos a informação nas melhores fontes, sejam bases de dados ou sites da Internet, com os mais aperfeiçoados mecanismos de busca, procurando os sinais de uma informação importante para uma situação específica.

Desde a criação da escrita houve uma modificação nas relações informacionais, pois não existe mais a necessidade da informação estar sempre sendo transmitida no contexto presencial do emissor/receptor. Segundo Goody,

A proposição específica é que a escrita e, mais especificamente, a literatura alfabética, torna possível a investigação do discurso de diferentes tipos e modos, dando à comunicação oral uma forma semipermanente: esta investigação aumenta do escopo da atividade crítica, daí a racionalidade, o ceticismo e a lógica para ressuscitar memórias daquelas dicotomias questionáveis.

...ao mesmo tempo aumenta a potencialidade para acumular conhecimento, especialmente o conhecimento de um tipo abstrato, porque mudou a natureza da comunicação para além do contato face a face assim como também o sistema para armazenagem de informação. (GOODY, J., 1979, p. 37)

Assim, como a informação necessita de um contexto para ser compreendida, as palavras ou conceitos só têm uma existência plena de significado quando estão contextualizadas. 
Por exemplo, a frase: "vamos fazer uma rede" pode ter diferentes entendimentos de acordo com o contexto em que seja pronunciada, ou melhor, de acordo com o grupo social/receptor em que for expressa. Caso seja dita em um grupo de produtores de trabalhos manuais do Nordeste do Brasil, poderá ser entendida como o ato de fazer um objeto utilitário para dormir ou descansar. Já em um grupo de profissionais da informação, com certeza será entendida como um apelo que aponta para a necessidade de se fazer/pensar um sistema de comunicação da informação. ${ }^{9}$

Por isso, segundo Elias ${ }^{10}$, devemos sempre estar atentos para as possíveis configurações contextuais em nossa sociedade, que está em constante mobilidade, fazendo com que as relações semânticas sejam construídas continuamente. Isso nos leva à idéia de rede do autor: Totalidade da relação entre indivíduo e sociedade. Esse conceito só seria possível pensando no permanente crescimento do indivíduo, ou seja, a idéia de permanente construção. Nesse particular, apesar da multiplicidade de sentidos que podem ser identificados para a idéia de "rede", Santos (1997) identifica duas grandes matrizes: uma que enfatiza o aspecto material, e outra que, além deste aspecto, também levaria em conta o aspecto social. Nesta última categoria estaria a idéia de que rede seria

...toda infra-estrutura, permitindo o transporte de matéria, de energia ou de informação, e que se inscreve sobre um território onde se caracteriza pela topologia dos seus pontos de acesso ou pontos terminais, seus arcos de transmissão, seus nós de bifurcação ou de comunicação. (SANTOS, 1997 p. 208-222)

Com certeza, essas redes transportam mensagens produzidas por pessoas, as pessoas têm intenções ao comunicar, estão inseridas em uma estrutura sócio-econômica. Então como nos diz Santos "as redes são técnicas, mas também são sociais" (SANTOS, 1997, p.222). Ao possibilitar uma maior interação entre os seus usuários, as tecnologias digitais de informação e da comunicação, como por exemplo, nas teleconferências, ou troca de informações por e-mail em tempo real, resgatam a comunicação primordial feita através do olhar, do gesto, da presença humana. Esse resgate é fundamental, pois nos re-coloca em contato com um tipo de comunicação fundamental, mais completa, remonta ao tempo em que os seres humanos ainda não haviam inventado a escrita.

O milagre do nosso tempo é conjugar a presença, a narrativa oral, o gesto e o movimento, na troca comunicativa à distância. $\mathrm{O}$ ser humano é uma espécie gregária $\mathrm{e}$ grande parte de seu sucesso na cadeia evolutiva das espécies se deve, certamente, à sua capacidade de organização em grupos, o que facilita a defesa e proteção, e também à sua enorme capacidade de adaptação aos mais diversos climas e meio ambiente.

Quando uma comunidade de camponeses semeia o campo, está confiando sua vida à terra e ao tempo. A colheita só irá ocorrer após diversas lunações. A invenção da agricultura, elemento fundamental

9 Sem contar que poderíamos imaginar a rede cognitiva de significados que poderia surgir, diferentemente, nos dois grupos distintos.

10 ELIAS, Nobert, 1996. 
daquilo a que chamamos de revolução neolítica, é também a exploração de uma nova relação com o tempo. (LÉVY, 1993, p. 53)

A informação já se faz bastante presente e necessária desde essa época, mesmo quando ainda não existia o registro para as informações, estas eram transmitidas e perpetuadas através de narrativas míticas, que davam conta, tanto das informações práticas para o grupo social, como onde havia mais caça em determinada época do ano, como também para a criação de um imaginário arquétipo coletivo que atendesse às necessidades da comunidade. A partir do momento em que passa a existir o registro, o tempo pode ser contado.

$\mathrm{Na}$ medida em que as comunidades humanas aumentaram em tamanho e a sua população, também cresceu a presença da técnica na vida das pessoas. As mercadorias se multiplicam e passam a ser trocadas por outras diferentes. Inicia-se, assim, um modo de produção baseada em bens e produtos, que irá evoluir até os nossos dias, com o desenvolvimento da técnica para a tecnologia digital contemporânea.

Essas tecnologias ganharam um forte impulso nos anos 1970. Nesse momento, surgiu o computador pessoal, promovendo mudanças, que provocaram o desenvolvimento das tecnologias digitais de comunicação da informação. A qualidade, o fácil acesso e o barateamento cada vez maior parece ser o grande atrativo desses novos artefatos operacionais criados pelos seres humanos. As novas tecnologias passam a tratar com uma mercadoria cada vez mais virtual (apesar dos seus suportes materiais), e que pode mudar de lugar rapidamente através das redes de comunicação eletrônica, como a Internet. Esta mercadoria específica é a informação. Em um texto que pode ser considerado profético (já que na época ainda não se tinha disponível a tecnologia da web), Raffestin focaliza o tema da transferência de bens/mercadorias e de informação de maneira interessante. Para ele, sempre existiram as duas formas de transporte de bens e serviços, só que agora a ênfase está sendo dada à transferência de informação:

Redes de circulação e redes de comunicação, no fim, se compenetram, se articulam, interagem. Mas, sobretudo, criam interfaces entre circulação e comunicação, que dão ao poder uma trama específica. Não são dessas interfaces que querem se apropriar aqueles que, em toda crise ou revolução, querem substituir o grupo dominante? Quem procura tomar o poder se apropria pouco a pouco das redes de circulação e de comunicação: controle dos eixos rodoviários e ferroviários, controle das redes de alimentação de energia, controle das centrais telefônicas, das estações de rádio e de televisão. Controlar as redes é controlar os homens e é impor-lhes uma nova ordem que substituirá a antiga. (RAFFESTIN, 1993, p. 213)

Essa realidade aponta para a velha questão que parece estar sempre presente na história da humanidade: o poder político. Sendo a informação cada vez mais uma forma de acesso ao conhecimento relevante para o setor produtivo, a dominação dos meios onde ela circula pode se tornar uma ação estratégica para atingir determinados objetivos, por parte de grupos econômicos ou políticos, como também por países interessados em manter a hegemonia política em escala global. As redes de comunicação podem facilitar 
ou dificultar a concretização desses interesses dissimulados, que estão cada vez mais difíceis de serem observados.

Afinal, não se pode esquecer que por trás de toda tecnologia existem pessoas. Pensamos, às vezes, que os mediadores da informação estão prestes a se acabar, já que os mecanismos de busca na Internet são cada vez mais precisos e sofisticados, mas o que há na realidade é um problema cada vez maior de excesso de informação e a necessidade de organizá-la e, principalmente, disponibilizá-la de modo eficiente para que se torne útil para a sociedade, principalmente em um país em desenvolvimento como o Brasil.

\section{ESTOQUES DE INFORMAÇÃO EM FLUXO: UMA JORNADA NO CIBERESPAÇO ${ }^{11}$}

Fala-se muito sobre o "impacto das novas tecnologias de informação e comunicação", mas, para Levy, o conceito de "impacto" não é propriamente adequado à situação, pois essas tecnologias são criadas e usadas por pessoas que fazem parte da sociedade e cultura humanas.

Dessa forma,

As verdadeiras relações, portanto, não são criadas entre 'a tecnologia' (que seria da ordem da causa) e 'a cultura' (que sofreria os efeitos), mas sim entre um grande número de atores humanos que inventam, produzem, utilizam e interpretam de diferentes formas as técnicas. (LEVY, 1999, p.23. Grifo nosso.)

Como na série da televisão, o importante não são as estrelas e os planetas, porém as pessoas que criam e seguem roteiros para navegação entre os astros do espaço sideral. Nosso grifo é para destacar que, ao falarmos em ou ao criamos novas tecnologias de comunicação e informação, não se pode, no entanto, nunca esquecer os usuários que navegam nas naves e roteiros que produzimos. E deve ser lembrado que existem na sociedade grupos que se posicionam contra ou a favor dessas novas tecnologias. Acreditamos que ainda é cedo para se avaliar as reais mudanças trazidas por esses novos elementos comunicacionais, uma vez que nos encontramos no início dessa "cibercultura", com suas implicações no processo de acumulação do capital, nas relações de trabalho, na produção de conhecimento, nas formas de lazer, enfim, em todos os segmentos da sociedade. Nesse sentido, certamente que

...a verdadeira questão não é ser contra ou a favor [das novas tecnologias], mas reconhecer as mudanças qualitativas na ecologia dos signos, o ambiente inédito que resulta da extensão das novas redes de comunicação para a vida social e cultural. ...

Por trás das técnicas agem e reagem idéias, projetos sociais, utopias, interesses econômicos, estratégias de poder, toda a gama dos jogos dos

\footnotetext{
11 O título alude à série Jornada nas Estrelas: na nossa metáfora, o espaço cósmico é visto como um espaço comunicacional - o ciberespaço —, onde as estrelas e planetas são os links e cada usuário [cosmonauta] navega em um universo de informação, seguindo um roteiro particular e diferenciado num espaço infinito de possibilidades.
} 
homens em sociedade. Portanto, qualquer atribuição de um sentido único à técnica só pode ser dúbia. (LEVY, 1999, p.24)

A partir do momento em que os seres humanos se organizaram em grupos sociais, a história da humanidade passou a ser ligada à criação e desenvolvimento de técnicas. Desde o reconhecimento e à elaboração de estratégias para coletar frutos e raízes, à construção de artefatos para melhor utilização das potencialidades da terra (como o arado), a criação de técnicas e instrumentos foi e continua a ser de suma importância para a evolução da espécie. Assim, "uma técnica é produzida dentro de uma cultura, e uma sociedade encontra-se condicionada por suas técnicas. E digo condicionada, não determinada. Essa diferença é fundamental” (LEVY, 1999, p.25).

A história das sociedades humanas nos mostra vários exemplos de técnicas que surgiram primeiramente em determinados países, mas que só foram conhecer o seu desenvolvimento pleno e provocar uma ruptura com o modelo reinante, naquela época, quando foram introduzidas/criadas em outros espaços geográficos e culturais. Hoje, se observa um cenário em que a inteligência coletiva vai sendo construída em um espaço, ou melhor, ciberespaço onde dois elementos (que Levy chama dispositivos) devem ser destacados. O primeiro dispositivo é o

Q Informacional, que "qualifica a estrutura da mensagem ou o modo de relação dos elementos de informação" (LEVY, 1999, p.62).

Esse elemento se refere ao modo como os estoques de informação se estruturam e como podem se relacionar com outros estoques, ou seja, diz respeito ao fato da informação estar disponibilizada, organizada de várias maneiras (resumos, tesauros, catálogos...) e relacionada com outras informações de forma específica. A emergência do ciberespaço vai possibilitar o surgimento de dois dispositivos informacionais originais: o mundo virtual (que dispõe a informação em um espaço contínuo) e a informação em fluxo (dados em estado contínuo de modificação), e isso nos leva à idéia de infinito (espaço que nunca será completamente preenchido e que se encontra em um estado permanente de mudança).

O segundo dispositivo é o

Q Comunicacional, que "designa a relação entre os participantes da comunicação". As categorias de dispositivos comunicacionais são três: um-todos; um-um; todos-todos" (LEVY, 1999, p.63).

As novas tecnologias trazem a possibilidade de penetrarmos em uma nova realidade, nos abre oportunidade de experimentar um novo campo de trabalho e relações sociais, uma realidade virtual que, "no sentido mais forte do termo, especifica um tipo particular de simulação interativa, na qual o explorador tem a sensação física de estar imerso na situação definida por um banco de dados" (LEVY, 1999, p.70).

Entretanto, apesar da infinita possibilidade de oferecer novas experiências, essa nova "dimensão" não nos leva a um abandono do real, uma vez que 
Assim como o cinema ou a televisão, a realidade virtual é da ordem da convenção, com seus códigos, seus rituais de entrada e saída. Não podemos confundir a realidade virtual com a realidade cotidiana, da mesma forma como não podemos confundir um filme ou um jogo com a verdadeira realidade. (LEVY, 1999, p.71)

A diferença está na interatividade. De uma maneira geral, o termo interatividade "ressalta a participação ativa do beneficiário de uma transação de informação" (LEVY, 1999, p.71). A interatividade se apresenta nos elementos informacionais contidos nas redes digitais de maneira nunca vista antes, e dizemos antes porque a possibilidade interativa também está presente em um livro (através de carta ao autor, por exemplo), na televisão (que se utiliza de cartas, ligações gratuitas ou e-mail). Nas redes digitais de comunicação, essa interatividade se apresenta na utilização, por parte dos usuários, de tecnologias intelectuais, de maneira que estes participam cada vez mais do processo de produção e comunicação de informação. Esse fenômeno ocorre em situações em que o usuário é levado a uma participação ativa, seja na construção de hipertextos, por exemplo, ou na utilização direta de programas que só funcionam adequadamente no processo de interação com o usuário. A interatividade e a comunicação presencial, que são tidas como características somente da linguagem falada nas relações interpessoais, ganham uma nova dimensão com o surgimento das salas de chats, em que a comunicação é feita em tempo real (como na presencial), mas concretizada através da escrita. Em decorrência, a distinção entre a linguagem falada e a escrita, no ambiente virtual, está se tornando cada vez mais difícil de ser percebida.

Os textos eletrônicos oferecem uma participação mais ativa por parte do receptor, especialmente na Internet, que se traduz na possibilidade de agregar novas informações através de links que permitem comentários, da participação em chats e listas de discussão, formas de comunicação que têm crescido bastante. Atualmente, um gênero antes tradicional, que é a ficção literária, adotou recursos interativos. Na Internet, existem muitos exemplos da chamada hiperfiction, que é uma ficção produzida em formato de hipertexto. A obra é construída de forma que o leitor participe ativamente, seja através de perguntas, ou mesmo escrevendo partes da história, assim como também a escolha do final.

Em relação à avaliação do potencial de interatividade de um produto de informação (aqui considerados o conteúdo e o formato de um site, por exemplo), Levy nos alerta que "o virtual não substitui o real, ele multiplica as oportunidades para atualizá-lo." (LEVY, 1999, p.88). Nesse sentido, "A possibilidade de reapropriação e de recombinação material da mensagem por seu receptor é um parâmetro fundamental para avaliar o grau de interatividade de um produto" (LEVY, 1999, p.79).

No ciberespaço constituído pela Internet, milhões de informações se cruzam todos os dias, na medida em que as pessoas "visitam" sítios virtuais e utilizam bancos de dados, trocam correspondência e participam de grupos de trabalho. Tal feito só é possível através da grande rede de comunicação, que possibilita a interconexão de computadores em todo o mundo. Este campo comunicacional, o ciberespaço, é um espaço informacional que possibilita novas formas de relação e apresenta duas funções 
principais, que são acesso à distância aos diversos recursos de um computador e transferência de dados.

\section{VIVENDO NA SOCIEDADE DA INFORMAÇÃO}

Em resumo, como visto, os seres humanos sempre evoluíram através da aprendizagem e aquisição de novos saberes. Hoje, as tecnologias digitais de informação estão cada vez mais presentes em todos os segmentos da sociedade, concorrendo para que surjam novas formas em relação à produção e aquisição de saberes. Assim, surgem novos processos, tais como a aprendizagem e o trabalho cooperativos assistidos por computador, que se traduz em aprendizagem cooperativa. Isso nos leva a uma realidade possível, onde cursos e treinamentos são ministrados à distância, e o trabalho pode ser efetuado por pessoas que estão em diferentes locais. De imediato, percebemos a possibilidade, também, de uma diminuição de custos operacionais, já que as pessoas não precisariam mais se deslocar para um "local de trabalho".

A presença de três princípios faz com que o crescimento do ciberespaço se torne possível. São eles:

Q a interconexão;

Q a criação de comunidades virtuais;

Q a inteligência coletiva.

A interconexão é fundamental, pois não é possível pensar em ciberespaço sem a idéia de rede. Por outro lado, para o funcionamento da grande rede de informação a que chamamos Internet, é necessário que todos os computadores estejam conectados e se comunicando entre si. $\mathrm{O}$ segundo princípio, diz respeito à própria construção de massa crítica representada pelo número cada vez maior de pessoas, que se reúnem por interesses em comum, participando de listas de discussão. E neste processo vão construindo novas formas de opinião pública. É salutar lembrar que sem a interconexão o diálogo entre pessoas de uma mesma comunidade virtual e das comunidades virtuais entre si seria impossível. Nesse sentido, "a interconexão tece um universal por contato" (LEVY, 1996, p.127) e cada ponto da rede de comunicação pode contribuir para seu crescimento como um todo, em um processo que se aproxima do que Johnson chama de "auto-organização" (JOHNSON, 2003, p. 63).

Vivemos numa sociedade em que a informação tem sua relevância apontada por todos, tendo no conhecimento a sua base ${ }^{12}$. Nesse sentido, já em 1975, Wersig e Nevelling falavam de uma nova relevância para um fenômeno antigo. Segundo os autores:

Problemas informacionais existem há muito tempo, sempre estiveram mais ou menos presentes, mas sua importância real ou percebida mudou e essa mudança foi responsável pelo surgimento da Ciência da Informação, e não apenas dela. (WERSIG; NEVELING, 1975 p.127)

Essa informação pode vir a se transformar, ou não, em conhecimento, a partir de uma construção cognitiva individual em um dado contexto social, representando um

12 Como abordado por FARRADANE, 1980. 
inestimável e significativo valor à sociedade. Por isso mesmo, deve estar ao alcance de todos, através de agregados de informação ${ }^{13}$ e redes de comunicação ou distribuição dos estoques de informação disponíveis nesses agregados. A abordagem cognitivista na Ciência da Informação, que aborda a relação entre informação e conhecimento, tem se revelado uma área promissora no campo dos estudos informacionais, desde os estudos cognitivistas baseados nos processos mentais de assimilação da informação do indivíduo (como em Belkin e Barreto), às pesquisas acerca dos processos cognitivos que levam em consideração o contexto social no qual o processo informacional ocorre (cf. Hjorland e Albrechtsen, 1995).

Pois na sociedade contemporânea, as tecnologias digitais possibilitam aos usuários grande mobilidade na busca de informação em fontes remotas, como nunca visto, oferecendo-lhes a oportunidade de criar seus próprios espaços de produção e comunicação de informação. A qualquer hora que alguém entre na web terá sempre a possibilidade de encontrar outro alguém plugado, pois os fusos horários são diferentes no mundo, mas o ciberespaço permite que esses tempos se sincronizem e, por assim dizer, todos estejam no presente. Por outro lado, a Internet é um espaço comunicacional que permite, a partir do cumprimento de certos procedimentos técnicos, a qualquer pessoa construir uma página que a representa. Neste caso, não se pode mais falar em usuário passivo para o qual se cria e mantém um dado serviço, ou agregado de informação, porém em usuário participante, que organiza e comunica sua própria informação.

A riqueza que uma rede virtual de aprendizagem pode trazer para o processo de aprendizagem à distância, mediado pelas tecnologias digitais, é inestimável. A Internet, por exemplo, é um canal de comunicação fundamental neste contexto, uma rede onde as possibilidades de busca da informação são infinitas e da qual ainda não percebemos e utilizamos todo o potencial tecnológico. $\mathrm{Na}$ área da comunicação e da informação, já vislumbramos todo o seu potencial de mudanças que ocorrem, primeiramente, em atividades como produção de informação (pré-prints disponibilizados em rede), no trabalho dos mediadores da informação (editores, bibliotecários), na disseminação da informação (através de sites de instituições, ou ainda, de maneira mais radical, de sites pessoais mantidos por pesquisadores para tornar diretamente acessível aos usuários os resultados de suas pesquisas, blogs...). Enfim, todos esses exemplos nos dão uma idéia de quanto pode ser realmente rica uma orientação didática dirigida para redes virtuais de aprendizagem, possibilidades que podem vir a ser explorada de maneira diferente por cada comunidade virtual.

Assim, uma rede virtual de aprendizagem pode ser muito produtiva no sentido de facilitar o acesso a grande quantidade de informações e a troca de experiências entre os seus participantes, o que torna o aprendizado mais rico e significativo, principalmente quando a rede incentiva a participação de grupos multidisciplinares. Essa troca de experiências valoriza o capital intelectual dos usuários e tem grande repercussão na produção e circulação de informação entre os participantes. Assim, na nossa abordagem, o grande benefício de uma rede de aprendizagem vem a ser o próprio aprendizado dos participantes e a utilização de modelos de trabalho cooperativo e

13 Cf. BARRETO, 1996. 
colaborativo. E é nesse sentido que um quadro de referência teórico como o que propomos pode ser aplicado na prática da pesquisa na área da Ciência da Informação, orientado pela visão de uma sociedade que se organiza em redes de aprendizagem contínua.

Destarte, a inovação do presente trabalho está na aplicação de abordagens da Ciência da Informação à organização e uso do espaço virtual como espaço comunicacional, onde os estoques de informação estão sempre em fluxo e o papel do profissional da informação se define a partir de um compromisso com a responsabilidade social de facilitar a comunicação de informação para aqueles que dela necessitam, na sociedade.

\section{REFERÊNCIAS}

BARRETO, Aldo de Albuquerque. A oferta e a demanda da informação: condições técnicas, econômicas e políticas. Ciência da Informação, v.28, n.2, 1999. Disponível em: http://www.ibict.br/cienciadainformacao/viewarticle.php?id=336\&layout=abstract. Acesso em: 20/01/2007.

. Perspectivas da Ciência da Informação. Revista de Biblioteconomia de Brasília, v.21 n.2, 1997.

- A eficiência técnica, econômica e a viabilidade de produtos e serviços de informação. Ciência da Informação, v.25, n.3, 1996.

BELKIN, N.J.; ROBERTSON, S.E. Information science and the phenomenon of information. The Information Scientist, v.27, n.4, 1976.

CASTELLS, M. A sociedade em rede. São Paulo: Paz e Terra, 1999.

ELIAS, Nobert. A sociedade dos indivíduos. Rio de Janeiro, Jorge Zahar editor, 1996.

FARRADANE, J. Knowledge, information, and science. Journal of Information Science, n.2, 1980.

FREIRE, G.H. de A. Comunicação da informação em redes virtuais de aprendizagem. 2004. Tese (Doutorado Ciência da Informação). Rio de Janeiro, CNPq/IBICT - UFRJ/ECO, 2004.

GOODY, J. La raison graphique: la domestication de la pensée sauvage. Paris, Les Éd. de Minuit, 1979 (orig. "The domestication of the savage mind", Cambridge Univ. Press, 1977).

HJORLAND, B.; ALBRECHTESEN, H. Toward a new horizon in Information Science: domain-analysis. JASIS, v.46 n.6, july 1995.

JOHNSON, S. Emergência: a vida integrada de formigas, cérebros, cidades e softwares. Rio de Janeiro: Rio de Janeiro, 2003.

LÉVY, Pierre. As tecnologias da inteligência; O futuro do pensamento na era da informática. Rio de Janeiro: Ed. 34, 1993.

. Cibercultura. São Paulo: Ed. 34, 1999.

O que é o virtual? São Paulo: Ed. 34, 1996.

RAFFESTIN, C. Por uma geografia do poder. São Paulo: Ática, 1993.

SANTOS, M. A natureza do espaço: técnica e tempo; razão e emoção. São Paulo: Hucitec, 1997. Cap. 11 - Por uma geografia das redes. p. 208-222.

STEWART, T.A. Capital intelectual. Rio de Janeiro: Campus, 1998.

WERSIG, G; NEVELING, U. The phenomena of interest to information science. The Information Scientist, v.9, n.4, 1975. 


\begin{abstract}
Presents an aspect of the thesis in which a virtual learning network (here called information stocks in flow) facilitates the communication of information in groups of users that participate in it. Points out that the main characteristic of contemporary society is the application of information and knowledge in a cumulative feedback cycle of technological innovation. Discusses the value of intellectual capital in the process of social production, which means a constant demand of update in dynamic stocks of information stored in individuals. Defines the information professional role beginning with social responsibility in facilitating the communication of information to an user that needs it, in the process of construction of its own knowledge. Proposes that virtual learning networks take on the fundamental task of being a medium, not only as way of communication information, but, specially, in creating possibilities of production of new knowledge.
\end{abstract}

KEYWORDS: Virtual learning network. Information communication. Information management. Information science. Information professionals.

Originais recebidos em: 14/11/2007

Texto aprovado em: 13/03/2008 